All letters are subject to editing and may be shortened. General letters can be sent to bjgpdisciarcgp.org.uk (please include your postal address for publication), and letters responding directly to BJGP articles can be submitted online via eLetters. We regret we cannot notify authors regarding publication.

For submission instructions visit: bjgp.org/letters

\section{General practice in UK newspapers: the influence of major policy changes}

We read with interest the findings of Barry and Greenhalgh indicating the continuing negative portrayal of GPs in UK newspapers. ${ }^{1}$ The authors highlight that general practice is seen as a service in crisis, with low morale and high burnout, and that GPs are portrayed as being responsible for the crisis and resulting negative impacts on patient care.

Our previous studies suggested that UK newspaper coverage of general practice became unfavourable following the introduction of the new General Medical Services contract in 2004. ${ }^{2}$ Previous recognition of demanding working conditions and relatively poor rewards in general practice transformed into a predominantly negative portrayal, with concerns about unfairly excessive income and poor use of public money. The introduction of the Health and Social Care Bill in $2011^{3}$ continued this trend, with signs of eroding trust in GPs. Public perceptions of how GPs are paid will continue to damage public trust if the drive to meet pay-for-performance targets is perceived as undermining patient-centred care.

Persistent negative media coverage may also hinder GP recruitment and retention. We advise that media stories written by doctors may mitigate this unfavourable trend. We suggest that GPs should actively engage with the media to broaden the debate from costs and capacity alone to quality and equity of care.

Sarah L Alderson,

NIHR Academic Clinical Lecturer in Primary Care, Leeds Institute of Health Sciences.

Email: s.l.aldersonaleeds.ac.uk

\section{Adam Balkham,}

Psychiatry Core Trainee 1, Birmingham and Solihull Mental Health Trust.

Robbie Foy,
Professor of Primary Care, Leeds Institute of Health Sciences.

\section{REFERENCES}

1. Barry E, Greenhalgh T. General practice in UK newspapers: an empirical analysis of over 400 articles. Br J Gen Pract 2019; DOI: https://doi.org/10.3399/bjgp19X700757.

2. Tanner F, Foy R, Harrison W. 'Wads up, doc' - trends in British newspapers' reporting of general practitioners' pay. Prim Health Care Res Dev 2010; 11(4): 405-409.

3. Balkham A, Alderson S. 'The biggest car crash in NHS history': the media portrayal of GP pay before and after the introduction of the Health and Social Care Bill 2011. Prim Health Care Res Dev 2017: 8(1): 84-91.

DOI: https://doi.org/10.3399/bjgp19X701429

\section{Can QOF cancer care reviews help with continuity of care?}

I write as an experienced GP, suddenly plunged into the world of a cancer patient and wish to reflect on the importance of a strong continuing GP-patient relationship throughout the cancer journey, and the role of QOF cancer care reviews in facilitating this process.

As a GP I have often experienced a mix of professional satisfaction and guilt when I've made an unsolicited phone call to a patient to perform a cancer care review. The usual driver for the call was to tick the QOF box, but, as the conversation has unfolded, patients have invariably expressed appreciation for the call and, although there is infrequently anything specific they have needed from me, it has been helpful to offer reassurance that I am available, should the need arise in the future.

Hurtand et al highlight the risk of loss of continuity of care with a GP around the time of, and in the year after, a cancer diagnosis. As a GP, I had assumed that this was because of patients being absorbed into the hospital system, with multiple appointments and good support from cancer specialist clinicians. Although this is true in part, as a patient I have experienced a reality that is more mixed. I have encountered numerous skilled and caring professionals, but have also recognised that they work within a system that is stretched and struggling to meet the demands placed upon it. Nowhere is this more apparent than the MDT process where the need to discuss large numbers of patients can result in rapid decision making and in the patient voice being marginalised. At worst, vital decisions can be taken by clinicians who have never met the patient.

As l've had my personal challenging encounters with this process, I have come to appreciate the value of a GP who knows me and my illness, and is able to listen and, where necessary, advocate for me. QOF cancer care reviews can provide a valuable doorway allowing patients to access this support. As a patient, I vote that they should remain.

Sally P Dilley,

GP, Beauchamp House Surgery,

Chelmsford.

Email: sallydilleylatiscali.co.uk

\section{REFERENCE}

1. Hurtaud A, Aubin M, Ferrat E, et al. Continuity of care in general practice at cancer diagnosis (COOC-GP study): a national cohort study of 2853 patients. Br J Gen Pract 2019; DOI: https://doi. org/10.3399/bjgp19X700805.

DOI: https://doi.org/10.3399/bjgp19X701441

\section{Evidence about complex interventions}

I agree with almost everything McCartney and Finnikin say, ${ }^{1}$ and am delighted that they have said it so clearly and succinctly. But I am concerned that they risk making systematic interrogation of all new healthcare policies for evidence and costeffectiveness' sound easier than it is.

The traditional hierarchy of types of evidence places randomised controlled trials [RCTs] at the top, and this may well still be reasonable for evidence about a new drug or surgical procedure. But applying the same approach to evaluating complex interventions is increasingly acknowledged to bea mistake, because trial-based evidence 
cannot be assumed to be transferable to other settings. In a recent special issue of Social Science and Medicine focused on RCTs and evidence-based policy, Deaton and Cartwright discuss the limitations of RCTs as a method of establishing why things work'. ${ }^{2}$ Without a credible account of causation we cannot begin to work out whether a complex intervention that has certain effects in one setting will have those same effects somewhere else.

As well as leading to rapid abandonment of ineffective or harmful new policies, it would be nice if 'real-life testing' was used in a more complicated and constructive way, helping us understand the way elements of the intervention and elements of the context interact to produce both good and bad effects. The alternative is to continue to handle new ideas about healthcare delivery the way we do now, jumping onto each bandwagon that rolls past, only to jump rapidly off again when it turns out not to be useful in our particular setting.

Louisa Polak,

GP, Guildhall and Barrow Surgery, Bury St Edmunds.

Email: Lpolakladoctors.org.uk

\section{REFERENCES}

1. McCartney M. Finnikin S. Evidence and values in the NHS: choosing treatments and interventions well. Br J Gen Pract 2019; DOI: https://doi. org/10.3399/bjgp19X700313.

2. Deaton A, Cartwright N. Understanding and misunderstanding randomized controlled trials. Soc Sci Med 2018: 210: 2-21.

\section{Financial cuts limit numbers going under the knife in plastic surgery}

We were interested to read the editorial by McCartney and Finnikin about choosing NHS interventions wisely. ${ }^{1}$ As plastic surgery trainees, we often encounter dissatisfied patients turned away from clinic for procedures that are no longer NHS funded, and see consultant colleagues disappointed at being unable to practise many aspects of their speciality. The British
Association of Plastic, Reconstructive and Aesthetic Surgeons (BAPRAS) has issued commissioning guidelines for patients undergoing body-contouring procedures following massive weight loss. These procedures lead to sustained weight loss, as well as reducing the rate of other complications such as intertrigo, ${ }^{2}$ but are still deemed cosmetic by CCGs, and will be funded only if an Individual Funding Request (IFR) application proves exceptional clinical need. ${ }^{3}$ We think that we should be supporting patients wishing to undergo these operations. Beside psychological and medical benefits to patients, unnecessary appointments in general practice are thought to cost the NHS over $€ 300$ million a year. 4

We wish to highlight the BAPRAS Massive Weight Loss Body Contouring UK commissioning guidelines. ${ }^{5}$ Encouraging patients to meet the criteria prior to referral can reduce unnecessary clinic appointments, re-referral, and patient dissatisfaction. Successful adherence to these guidelines will give the IFR the greatest chance of being accepted and allowing surgery to proceed.

Nader Henry,

Plastic Surgery ST3 Registrar, Health

Education England West Midlands,

University Hospitals Birmingham, NHS

Foundation Trust, Queen Elizabeth

Hospital Birmingham.

Email: naderhenryladoctors.org.uk

\section{Ishan Radotra,}

Plastic Surgery ST3 Registrar, Health Education England West Midlands, Sandwell and West Birmingham Hospitals NHS Trust, Sandwell District General Hospital.

\section{Sheirin Khalil,}

GPST2 Registrar, Health Education England East of England, James Paget University Hospitals NHS Foundation Trust, James Paget University Hospital.

\section{Azzam Farroha,}

Consultant Burns, Plastic and Reconstructive Surgeon, University Hospitals Birmingham, NHS Foundation Trust, Queen Elizabeth Hospital Birmingham.

\section{REFERENCES}

1. McCartney M, Finnikin S. Evidence and values in the NHS: choosing treatments and interventions well. Br J Gen Pract 2019; DOI: https://doi. org/10.3399/bjgp19X700313.

2. Balagué N, Combescure C, Huber O, et al. Plastic surgery improves long-term weight control after bariatric surgery. Plast Reconstr Surg 2013; 132(4): 826-833.

3. NHS Birmingham CrossCity Clinical Commissioning Group. Clinical Commissioning Group (CCG) procedures of lower clinical value policy. 1st edn. 2016. http://staff. bhamsouthcentralccg.nhs.uk/plans-and-policies/ doc_download/1698-ccg-plcv-policy laccessed 12 Feb 2019).

4. Practice Business. Pointless GP appointments costing the NHS $€ 306 m$. 2017. http:// practicebusiness.co.uk/gp-appointments-costingthe-nhs-306m-a-year-blamed-on-admin-cuts/ laccessed 12 Feb 2019).

5. British Association of Plastic, Reconstructive and Aesthetic Surgeons. UK commissioning guide: massive weight loss body contouring. 2nd edn. London: Royal College of Surgeons of England 2017. http://www.bapras.org.uk/docs/defaultsource/commissioning-and-policy/rewrite-for2017--final-version.pdf?sfvrsn=4 laccessed 12 Feb 2019).

DOI: https://doi.org/10.3399/bjgp19X701465

\section{Correction}

Research by de Lusignan et al. RCGP Research and Surveillance Centre Annual Report 2014-2015: disparities in presentations to primary care. $\mathrm{Br}$ J Gen Pract 2017; DOI: https://doi.org/10.3399/ bjgp16X688573 had two errors: 1) the authors described a 5-year baseline as a 10-year one, and 2) the years data were not correctly aligned so far as the weeks were concerned. The online version has been corrected.

DOI: https://doi.org/10.3399/bjgp19X701477 